\title{
Erratum to: Braf, Kras and Helicobacter pylori epigenetic changes-associated chronic gastritis in Egyptian patients with and without gastric cancer
}

\author{
Dina Sabry ${ }^{1} \cdot$ Rasha Ahmed $^{2} \cdot$ Sayed Abdalla $^{3} \cdot$ Wael Fathy $^{6} \cdot$ Ahmed Eldemery $^{4}$. \\ Azza Elamir ${ }^{5}$
}

Published online: 25 April 2017

(C) Springer Science+Business Media Dordrecht 2017

\section{Erratum to: World J Microbiol Biotechnol (2016) 32:92 \\ DOI 10.1007/s11274-016-2048-x}

The corrected affiliation for Wael Fathy: Tropical Medicine, Beni-Suef University, Egypt.

Unfortunately, Dr. Wael Fathy's affiliation had been published incorrectly in the original publication. It has been corrected in this erratum.

The online version of the original article can be found under doi:10.1007/s11274-016-2048-x.

Dina Sabry

dinasabry@kasralainy.edu.eg; dinnasabry69@yahoo.com

1 Medical Biochemistry and Molecular Biology Department,

Faculty of Medicine, Cairo University, Giza, Egypt

2 Endemic Medicine \& Hepatology Department, Faculty of Medicine, Cairo University, Giza, Egypt

3 Internal Medicine Department, Faculty of Medicine, Cairo University, Giza, Egypt

4 Medical Biochemistry Department, Faculty of Medicine, October 6 University, Giza, Egypt

5 Medical Biochemistry Department, Faculty of Medicine, El Fayoum University, Al Fayoum, Egypt

6 Tropical Medicine, Beni-Suef University, Beni-Suef, Egypt 